\title{
How long will my repair last, doctor? Additional data on the durability of mitral valve repair
}

\author{
Stephanie Mick, MD, Kenneth McCurry, MD, Jose Navia, MD, and Marc Gillinov, MD
}

\footnotetext{
From the Department of Thoracic and Cardiovascular Surgery, Cleveland Clinic, Cleveland, Ohio.

Disclosures: Dr Gillinov serves as a consultant to Edwards Lifesciences, Medtronic, St. Jude Medical, and Abbott, and receives research funding from Tendyne and St. Jude Medical. Dr Mick serves as a consultant to Medtronic. The other authors have nothing to disclose with regard to commercial support.

Received for publication May 4, 2017; accepted for publication May 8, 2017; available ahead of print June 13 , 2017.

Address for reprints: Marc Gillinov, MD, Department of Thoracic and Cardiovascular Surgery, Cleveland Clinic, 9500 Euclid Ave, Cleveland, OH 44195 (E-mail: gillinom@ccf.org).

J Thorac Cardiovasc Surg 2017;154:831

$0022-5223 / \$ 36.00$

Copyright (c) 2017 by The American Association for Thoracic Surgery

http://dx.doi.org/10.1016/j.jtcvs.2017.05.027
}

Preoperative discussions between surgeons and patients before mitral valve surgery often include commentary on what patients should expect in terms of durability following valve repair. Patients are often worried about their "broken" valve and wonder whether the valve might "break" again and lead them back to the operating room. Surgeons are anxious to provide accurate and individualized information to guide patients to clear and appropriate expectations.

In this issue of the Journal, Tatum and colleagues ${ }^{1}$ provide data that add to the body of knowledge on this topic. In their single-center series of 446 patients who underwent mitral valve repair, survival was excellent at $95 \%$ at 5 years and $94 \%$ at 10 years. The overall incidence of reoperation (taking death into consideration as a competing risk) was $5.1 \%$ at 5 years and $9.6 \%$ at 10 years. Importantly, those patients who underwent posterior leaflet repair experienced a lower incidence of reoperation, $4.3 \%$ at 5 years and $5.7 \%$ at 10 years.

The overall incidence of progression of mitral regurgitation by 2 or more grades (again with mortality as a competing risk) was $21 \%$ at 5 years and $35.8 \%$ at 10 years, whereas overall progression to the more clinically relevant moderate-to-severe or severe mitral regurgitation was $7 \%$ at 5 years and $26 \%$ at 10 years. Echoing the reoperation data, there was a strong trend toward posterior leaflet repair being protective against progression of mitral regurgitation. This finding is consistent with previous reports associating anterior or bileaflet pathologies with increased risk of progression of mitral regurgitation following repair. ${ }^{2,3}$

Although limited by lack of complete follow-up data (with postoperative echocardiograms unavailable in $25 \%$ of the patients) and the authors' reliance on outside transthoracic echocardiography reports, the present work, along with previous research, provides the cardiac surgeon with an additional measure of confidence in guiding patients' expectations both preoperatively and postoperatively. If a posterior leaflet repair appears to be likely or has been performed, the surgeon can confidently quote a low risk

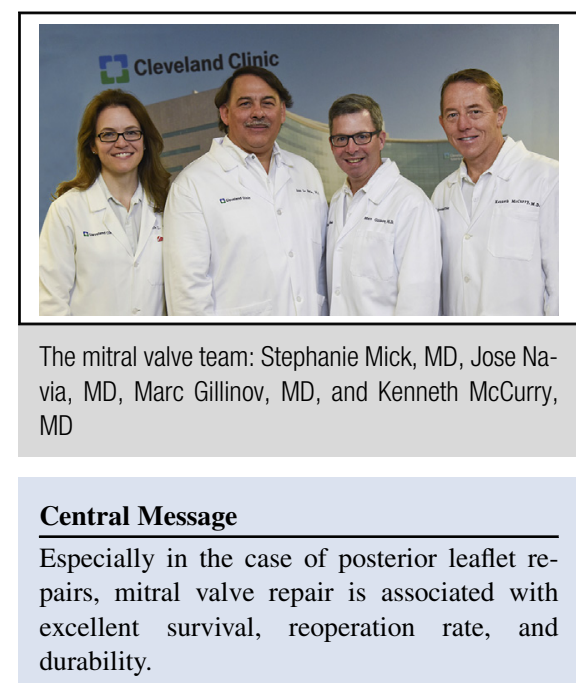

See Article page 822 .

of reoperation, and if not, he or she may temper his or her prediction.

The excellent results of mitral valve repair should be kept in mind in this era of heightened enthusiasm for percutaneous structural interventions and increasing interest in the application of these new technologies in patients who are candidates for conventional surgery. Although the MitraClip (Abbot Vascular, Abbott Park, Ill) remains the sole percutaneous therapy approved for use in the United States for degenerative mitral valve disease, multiple technologies are currently in development. As such devices come out of the "pipeline" and into active use in trials, surgeons will be called on to recommend for or against consideration of percutaneous measures. It will be of critical importance to keep the kinds of data provided by Tatum and colleagues ${ }^{1}$ in mind. Particularly in the case of posterior leaflet pathology, mitral valve repair represents the gold standard for the treatment of degenerative mitral valve disease, and the bar is set high for competing therapies.

\section{References}

1. Tatum JM, Bowdish ME, Mack WJ, Quinn AM, Cohen RG, Hackmann AE, et al Outcomes after mitral valve repair: a single-center16-year experience. Thorac Cardiovasc Surg. 2017;154:822-30.e2.

2. David TE, Armstrong S, McCrindle BW, Manlhiot C. Late outcomes of mitral valve repair for mitral regurgitation due to degenerative disease. Circulation. 2013; 127:1485-92.

3. Suri RM, Clavel M-A, Schaff HV, Michelena HI, Huebner M, Nishimura RA, et al. Effect of recurrent mitral regurgitation following degenerative mitral valve repair: long-term analysis of competing outcomes. J Am Coll Cardiol. 2016;67:488-98. 